Article

\title{
Perception of the Fair Social Distribution of Benefits and Costs of a Sports Event: An Analysis of the Mediating Effect between Perceived Impacts and Future Intentions
}

\author{
David Parra-Camacho $^{1}\left(\mathbb{D}\right.$, Mario Alguacil ${ }^{2}\left(\mathbb{D}\right.$ and Ferran Calabuig-Moreno ${ }^{1, *(1)}$ \\ 1 Department of Physical Education and Sports, Faculty of Physical Activity and Sport Sciences, \\ Universitat de València, 46010 Valencia, Spain; david.parra-camacho@uv.es \\ 2 Department of Teaching and Learning of Physical Education, Plastic and Music Education, \\ Universidad Católica de Valencia, 46110 Valencia, Spain; mario.alguacil@ucv.es \\ * Correspondence: ferran.calabuig@uv.es; Tel.: +34-96-398-3707
}

Received: 9 May 2020; Accepted: 27 May 2020; Published: 28 May 2020

\begin{abstract}
Residents' perception of a sporting event as a socially unfair phenomenon can lead to changes in residents' behavior towards the event and future sporting events. The aim of this study is to analyze the mediating effect of the perception variable on the fair social distribution (FSD) of benefits and costs between perceived positive and negative impacts and future intentions with respect to the celebration of the Formula 1 Grand Prix. A total of 371 residents were interviewed by using a questionnaire made up of indicators referring to positive and negative impacts, FSD, and future intentions. The psychometric properties of the scale were analyzed and structural equation modeling (SEM) was used to test the hypotheses. The results confirm that positive and negative impacts are significantly related to the perception of FSD, which, in turn, significantly influences future intentions. The mediating effect of FSD between perceived impacts and future intentions was also tested. The study suggests that it is important for organizers to pay attention to the social injustices and imbalances that may be associated with the holding of major sporting events in order to improve future behaviors toward sporting events.
\end{abstract}

Keywords: residents' perception; positive impacts; negative impacts; future intentions; social exchange theory; sporting events

\section{Introduction}

Sporting events are evaluated from various perspectives (economic, social, and environmental) in order to investigate their impact on host communities. Organizing a major sporting event is a complex process that requires a multi-stakeholder effort within the host community [1]. The sustainability of major sporting events largely depends on the views of the host community being taken into account in the event planning process [2].

Social impact can be conceptualized as any force potentially influencing the quality of life of local residents [3-5]. Support for a sporting event has been shown to be influenced by the perceived impacts $[6,7]$. Therefore, exploring the process of how residents' support is affected by perceptions of impacts is one of the aspects most emphasized in research in this area [8]. As local residents are a vital stakeholder group for the short- and long-term success of the organized event, analyzing their perceptions of the event's impacts is essential to the success of the event [2]. 
Most work analyzing the social perception of impacts of sporting events has concluded that the positive and negative impacts that a major sporting event could have on a community are two of the most important determinants of resident support or opposition to hosting the event [6,9-11].

In this paper, we analyze the perception of the positive and negative impacts of the European Formula 1 Grand Prix, the perception of the fair social distribution (FSD) of the benefits and costs associated with the event, and the future intentions of the residents with respect to the event.

According to the Getz and Page's [12] classification of events, Formula 1 Grand Prix events can be classified as regular major sports events or "hallmark events", which usually present a high tourist demand and high value that can be measured through socio-economic benefits, growth potential, the projection of the destination's image, and environmental and social sustainability. The European Formula 1 Grand Prix was held on a street circuit built specifically for the race that ran through the urban districts of the port area of Valencia.

Research has shown the relationship between the impacts perceived by the host community and support for sporting events [6,7]. Likewise, in recent years, some research has verified the mediating effect of various variables between the perceptions of the residents on the impacts and support for celebrations associated with the event: quality of life [8,13], overall attitude towards the event [2], involvement in sport [8], community participation [14], and positive and negative emotions [15]. As presented in the following section, there are few studies that have addressed the variable FSD of benefits and costs associated with sporting events and its relationship with perceived impacts and future intentions. For this reason, the purpose of this paper is to analyze the mediating effect of the perception variable on the FSD of benefits and costs between perceived positive and negative impacts and future intentions of holding the European Formula 1 Grand Prix.

\section{Theoretical Background and Hypothesis}

\subsection{Social Exchange Theory (SET)}

Social exchange theory (SET) has been used as a useful theoretical framework in several studies attempting to understand and explain why residents support sports events and how they perceive the impacts associated with them $[2,7,16]$. SET provides an explanation of why residents perceive the positive and negative impacts associated with hosting events differently. This theory indicates that if the benefits exceed the costs, the probability of supporting the hosting of the event is greater than if the costs exceed the benefits $[7,17]$. The three main elements of the exchange process are the economic, environmental, and socio-cultural benefits or costs, so this theory can explain residents' perceptions of the economic, environmental, and socio-cultural impacts associated with tourism phenomena [18], such as the holding of a sporting event.

This social exchange leads to an evaluation in which, if the resident is not satisfied, the associated impacts will be perceived negatively and unfavorable behaviors will develop for future events [19]. On the other hand, if residents are satisfied with the perceived benefits of the event, positive perceptions and supportive behaviors toward future events will be formed. However, if residents perceive the sharing of resources from an event to be deficient, it is likely that local activism and opposition will increase, stimulated by negative perceptions of the event's impacts [16]. In order to maintain positive future intentions or behavior with regard to the celebration of the event, it is necessary to constantly re-evaluate the perceived consequences of such an exchange [16].

Since SET can simultaneously explain the positive and negative impacts obtained from a major sporting event, it is useful for providing a better understanding of the support of residents for sporting events, which is a critical component in the development of destinations [17]. In this sense, this theory has been applied in numerous investigations on the social impact of sports events [7]. 


\subsection{Impacts of Sporting Events}

Various studies have established classifications of the impacts of events, differentiating between positive and negative impacts of events in different categories: socio-economic, tourism/commercial, environmental, infrastructure, socio-cultural, political/administrative, and psychological [20-22]. Other works have considered the category of impacts on the development of sport as an independent dimension [8,22] or included it within the category of socio-cultural impacts [23,24].

The category of socio-economic impacts often includes tourism-related and commercial impact indicators, as shown in several papers [22], because economic impact studies are considered to analyze the interrelationship between economic outcomes and the development of tourism as a form of economic development [8]. This category usually includes indicators related to the possibilities that a great sports event can offer for the increase of economic activity: an increase in consumption, business opportunities, commerce, the attraction of investors, job creation, an increase in the standard of living, and the development of tourist activity [20-22]. However, they can also generate negative socio-economic impacts, such as price increases during the event, real estate speculation, a lack of tourist attraction, better investment alternatives, inadequate capital and cost estimates for the event, high security costs, excessive debt, and increased taxes to cover costs [20].

From an environmental point of view, although the opportunity to generate positive impacts, such as encouraging recycling, promoting awareness of the importance of the environment, and the formation of a new environmental policy [2], is highlighted, on many occasions, environmental problems (e.g., an accumulation of waste, pollution problems, and the deterioration of natural spaces) tend to occur [25,26], in order to adapt and respond to the demands of the event. The operation of sports facilities, the consumption of products and services at sports events, and the modes of transport used by participants to attend sports events are all negative impacts that affect the environmental sustainability of the events. The study by Triantafyllidis, Ries and Kaplanidou [27] analyzed the carbon dioxide (CO2) emissions related to the transportation of spectators to university sports events, and found that there were significant differences between the two stadiums (one located on the university campus and the other off campus) in terms of the choice of mode of transportation for spectators and the distance travelled. Residents may negatively evaluate the holding of a major sporting event because of its negative impact on the environment, through increased pollution and the deterioration of culture, history, and natural resources [25]. Finally, it is important to highlight works such as Karadakis and Kaplanidou's [28] work on the perception of the legacy of host and non-host residents in terms of the Vancouver 2010 Olympic Games, which revealed that environmental legacies are the most important in all cities and over time, followed by economic and socio-cultural legacies.

Therefore, there is a growing recognition by sports institutions, teams, and sponsoring organizations of the need to better understand the environmental impacts of the activities and events they organize or sponsor [29]. In this regard, to ensure that damage to the environment is minimal, organizers need to plan appropriately and establish clear policies for the protection and conservation of the environment [28].

Impacts on infrastructure are often related to urban development and regeneration, which should be geared to the post-event use of facilities and infrastructure [25]. Some impacts in this area refer to improvements in telecommunications, adaptation, and embellishment of parts of the city, the improvement of roads, and the reurbanization of parks and public spaces [22].

The category of socio-cultural impacts includes aspects of an intangible nature, such as an increase in the level of interest and local participation in activities associated with the event, the promotion of local culture, an increase in hospitality and solidarity with visitors, and greater cultural awareness of the host community $[20,22]$. On the other hand, some negative socio-cultural impacts are related to vandalism, increased crime rates, prostitution, and inappropriate behavior, such as excessive alcohol or drug use [2].

The political and administrative impacts are related to aspects associated with the improvement of the international recognition of the region and its values, the development of skills among the 
organizers, and international understanding [20]. In this sense, the ultimate objective of the events is not only to evaluate the impact of the event, but also to take advantage of the opportunity to learn, in order to improve the organization of future events [30], as well as develop and improve the level of knowledge of local residents, enabling them to improve their quality of life [28]. In this sense, sports events provide opportunities for the personal growth and skill development of local residents through volunteerism that allows for positive experiences through social interactions [31]. For example, London created its own volunteer program with the aim of training the 70,000 volunteers who participated in the 2012 London Olympics. Such programs can increase the likelihood that these people will continue to volunteer at other local events in the city, providing an excellent example of a sustainable outcome for the local community [32].

Regarding the psychological impacts, included by some authors within the socio-cultural impacts, they are related to the improvement of the pride of the residents and the feeling of belonging and identification with the community, a festive atmosphere during the celebration of the event, and positive feelings for hosting the event $[2,20,22]$. In this line, the psychological benefits are, on many occasions, the most valued by the residents after the event $[13,25,33]$. In Kaplanidou's [33] work on residents' perceptions of the impact of various editions of the Olympic Games, it was found that Atlanta residents considered pride to be one of the most important legacies of the Olympic Games for improving the quality of life, while in the case of Sydney residents, global knowledge of Australian culture and pride were also important legacies.

On the other hand, it is important to highlight the works that have analyzed the influence of certain variables in the formation of personal perceptions about the impacts of sports events. In this regard, studies such as that of Kim and Kaplanidou [8] have shown the positive influence of sports participation in the construction of personal perceptions of the environmental, social, and economic impacts of sports events and the perceived quality of life. In turn, these variables were related to support for the celebration of the sports event. The study suggests that participation in sport can encourage support for a major sporting event by creating positive perceptions of the event's impacts.

\subsection{Fair Social Distribution and Future Intentions}

The hosting of a sporting event cannot result in social imbalance that is detrimental to some groups and beneficial to others, hence the need, in some cases, for some form of compensation for those who suffer from the effects of negative impacts without compensation in benefits [34]. In this sense, Fredline [34] has highlighted the importance of the relationship between perceptions of the impacts of the events and perceptions of social justice with respect to the distribution of such impacts, requiring effort on the part of the organizers, administration, and managers of the event to achieve an equitable distribution of costs and benefits.

In this regard, when referring to aspects such as fair social distribution, it is important to develop programs and policies that address the broad issues of social inclusion/exclusion of the host community, rather than just depending on the event's showcase to facilitate social inclusion [35]. To make successful use of large-scale sporting events, it is important not to get too carried away by the requirements of the event, as these may be determined by outside agents that do not have a long-term interest in the host city [36]. In this sense, the corporate social responsibility of companies that organize sports events is fundamental, since it encompasses the economic, social, legal, environmental, and ethical expectations of society regarding the organization of a sports event that aims to create and/or extend social benefits to the community [11].

The variable of the fair social distribution of benefits and costs has been analyzed in some works when determining the characteristics of groups of residents with different reactions to the impacts of sports events [34,37]. For example, Fredline [34] found that residents who perceived a fair social distribution of costs and benefits generated by sporting events were more likely to be members of the population group with a more positive perception of the event under analysis. 
Additionally, Parra et al. [38] found that the perception of a fair social distribution of benefits and costs associated with holding the Copa América soccer event in two Chilean host cities was directly related to future intentions and support for the holding of sports events. According to Chien et al. [39], if residents perceive the event to be partial or unfair, changes may occur in residents' reactions and behaviors around it. Given the framework of social exchange theory, a favorable or positive perception of the fair social distribution of the benefits and costs of hosting a sporting event should increase the likelihood of supporting the event and showing positive future intentions towards it [38]. However, the importance of this variable as a mediator between the perceived impacts and the future intentions or behavior of the residents has not been contrasted.

With regard to future intentions, it has been proven that there is a direct relationship between the perception of positive social impacts and this variable [40,41]. Other studies, such as that of Oshimi and Harada [42], have shown the influence of other variables, such as the perceived image, on residents' intentions. The influence of other constructs, such as the perception of the quality of information received, enthusiasm, and support for the celebration of sports events, on future intentions has also been verified [38]. The theory of social exchange postulates that if residents feel that the benefits outweigh the costs, the chances of increasing support for the event will increase, as will the chances of showing positive intentions towards the event.

Therefore, taking into account the theoretical framework and the relationships established between the different constructs (perceived impacts, fair social distribution of benefits and costs, and future intentions), the following hypotheses are raised, which are summarized in Figure 1 and listed below:

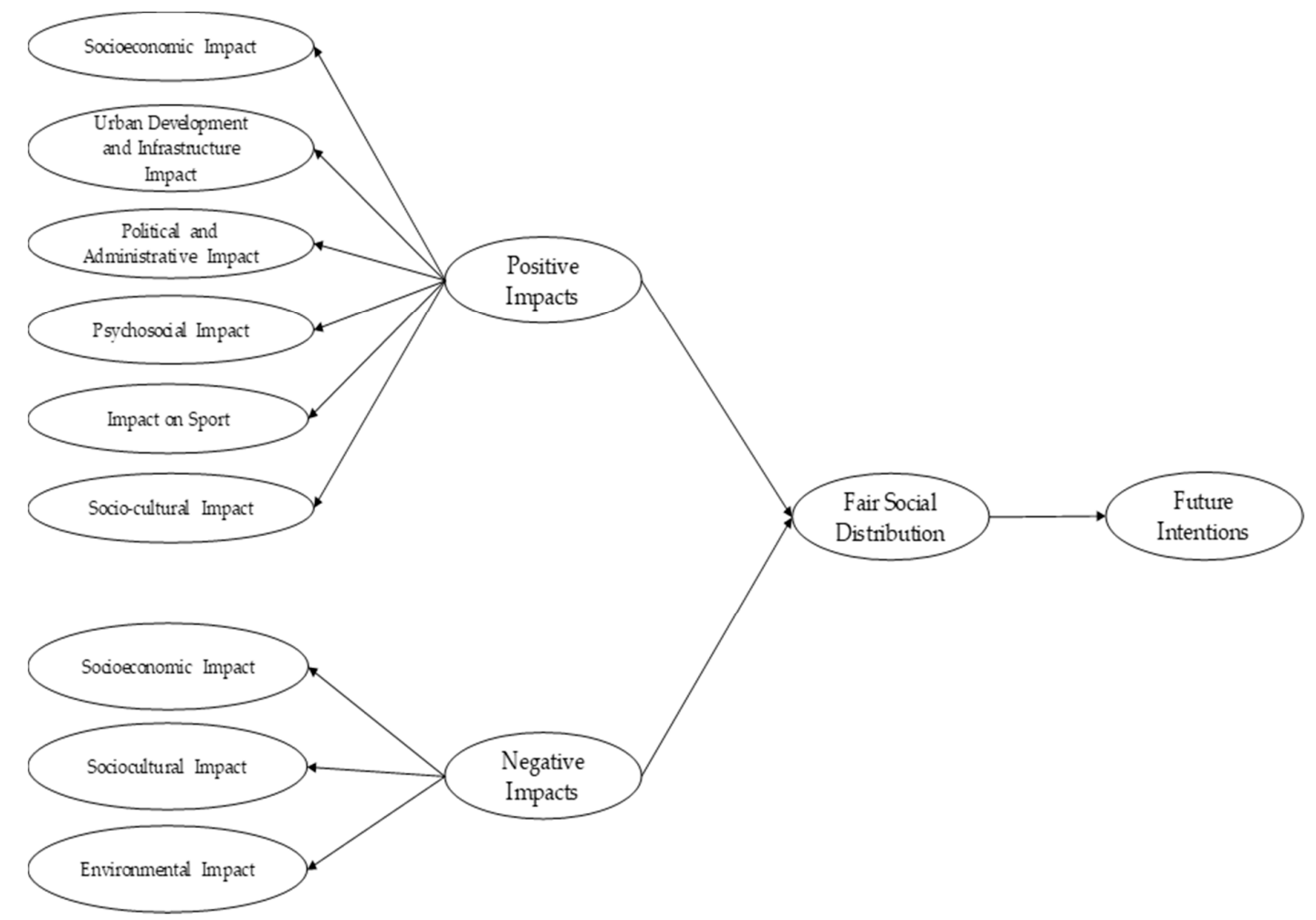

Figure 1. Model of causal relationships to predict fair social distribution and future intentions.

Hypothesis 1. The perception of positive impacts positively influences the perception of the FSD of benefits and costs of the event.

Hypothesis 2. The perception of negative impacts negatively influences the perception of the FSD of benefits and costs of the event. 
Hypothesis 3. The perception of the FSD of benefits and costs of the event positively influences future intentions.

Hypothesis 4. Perceived FSD of event benefits and costs mediates between perceived positive impacts and future intentions.

Hypothesis 5. The perceived FSD of event benefits and costs mediates between perceived negative impacts and future intentions.

\section{Materials and Methods}

\subsection{Sample, Procedures, and Questionnaire}

In this study, 371 residents were interviewed in the city of Valencia (Spain) and had the following sociodemographic characteristics: average age of 36.91 ( $\mathrm{SD}=16.29$ ); according to sex, $54.4 \%$ were men and $45.6 \%$ were women; according to occupation, more than a third of the sample was employed full time (28\%) or part time (10.5\%), 35.3\% were students, $15.4 \%$ were unemployed, and $10.8 \%$ had other occupations; and with regard to educational level, the majority had university studies (39.9\%), followed by secondary $(39.4 \%)$ and primary $(20.8 \%)$ studies.

To collect the information, a questionnaire was used, with indicators referring to positive impacts, negative impacts, FSD of benefits and costs associated with the event, and future intentions. The indicators of perceived positive and negative impacts were classified into various dimensions based on the impact categories of the sports events proposed in the theoretical frameworks of Preuss and Solberg [20] and Fredline [20,21] and, on the other hand, the different contributions made to the dimensions proposed by the case studies developed in this area of research [25,43-45]. For the scale of perceived positive impacts, 31 items were used, classified into six impact categories: socio-economic impact (7 items), urban development and infrastructure impact (6 items), political and administrative impact (5 items), psychosocial impact ( 3 items), sports impact (5 items), and sociocultural impact (5 items). In the case of the scale of perceived negative impacts, 11 indicators were used, distributed in three dimensions: socio-economic impact (5 items), environmental impact (3 items), and socio-cultural impact ( 3 items). The scale referring to the perceived FSD of benefits and costs was made up of two indicators adapted from Fredline [34], while the scale of future intentions was made up of four indicators adapted from the study by Brady et al. [46]. All indicators were assessed using a five-point Likert scale with five response options: 1 = Strongly disagree; 2 = Disagree; 3 = Neither disagree nor agree; 4 = Agree; and 5 = Strongly agree.

The sample was collected using a convenience sampling method, consistent with other previous work $[2,7,42]$. The selection of this type of sampling is justified for several reasons. Firstly, the absence of a suitable sampling frame, different from that of registered residents, which would make it possible to ascertain the actual number of residents living in Valencia. Secondly, the benefits provided by this type of sampling in terms of economic and temporal costs. One of the main weaknesses associated with convenience sampling is selection bias [25]. However, an attempt was made to balance the proportion of groups according to sex and age, in order to avoid this bias in the fieldwork. The questionnaires were completed in a self-administered manner, with the presence of a member of the research team.

\subsection{Data Analysis}

To check the psychometric properties of the scales, several confirmatory factor analyses were performed. Confirmatory factor analyses (CFAs) were performed using the EQS 6.2 program, applying the Robust Maximum Likelihood Estimation (MVR) method, in order to correct for the possible absence of multivariate normality, using statistics such as $\chi^{2}$ by Satorra Bentler [47]. Therefore, for the evaluation of global adjustment, different goodness-of-fit indexes recommended in the literature [48] were used, such as the significance of the Chi-square and its robust correction provided by Satorra-Bentler $\left(\mathrm{S}-\mathrm{B} \chi^{2}\right)$ [49]. Furthermore, other coefficients were calculated that allowed us to check the adequacy 
of the proposed models, such as the ratio of $\chi^{2}$ and its degrees of freedom $\left(\chi^{2} / \mathrm{df}\right)$ [50], which had acceptable values that were lower than five [51]. On the other hand, the coefficients of the robust goodness-of-fit indexes of the proposed model corresponding to the Non-Normalized Fit Index (NNFI), the Comparative Fit Index (CFI), and the Incremental Fit Index (IFI) were checked. Values above 0.90 are considered a good fit for these indicators [52]. Finally, the Root Mean Square Error of Approximation (RMSEA) is shown, being necessary to consider a good adjustment of the same score lower than 0.08 [53].

On the other hand, the reliability of the three scales was analyzed using Cronbach's Alpha, the Composite Reliability (CR), and the Average Variance Extracted (AVE) [54]. To check the convergent validity, the significance of the factor loadings of the indicators in their respective dimensions and the associated $t$-test values were analyzed [55]. Discriminant validity, which has to do with the clear distinction between any pair of constructs, was evaluated using the method suggested by Fornell and Larcker [56]. This method supports discriminant validity if the square root of the AVE value of a given factor is larger than the correlation coefficients between the factor and any other factor in the proposed scale. The value of correlations between factor pairs was also analyzed, with values lower than 0.85 being recommended [48].

After checking the validity and reliability of the scales, the fit of the proposed structural equation model was checked using the different adjustment indexes mentioned (S-B $\chi^{2}, \chi^{2} / \mathrm{df}$, RMSEA, NNFI, IFC, and IFI). The structural model was evaluated using the $\mathrm{R}^{2}$ estimates, the standardized beta coefficients $(\beta)$, and the significance level ( $t$-value). Finally, the Sobel test was used to check the mediating effect of a fair social distribution between perceived impacts and future intentions.

\section{Results}

\subsection{Psychometric Properties of Scales and Model Measurement}

First, the psychometric properties of the indicators of the perception scales on positive and negative impacts, FSD of benefits and costs, and future intentions were analyzed. Table 1 shows the values of the mean, standard deviation, corrected item-total correlation, Cronbach's alpha if the element is removed, asymmetry, and kurtosis. The values of the corrected item-total correlation coefficient were higher than the cut-off point recommended by the literature $(\geq 0.30)$. Additionally, the values of asymmetry and kurtosis are acceptable for most variables since they are lower than 3.0 [57].

After checking the properties of the items, a CFA was performed for the multidimensional scales of perception on positive and negative impacts. The hierarchical component model allows the researcher to use a more parsimonious model with better fit rates [54]. In this way, the adjustment of the first- and second-order models was tested on the scales of perceived impacts and then related to the constructs of FSD and future intentions. 
Table 1. Analysis of the properties of the items in the scales: Mean (M), standard deviation (SD), corrected item-total correlation (rjx), Cronbach's alpha if the item is removed $(\alpha-x)$, asymmetry (A), and kurtosis $(K)$.

\begin{tabular}{|c|c|c|c|c|c|c|c|}
\hline & Items & $\mathbf{M}$ & SD & $\mathbf{r}_{\mathbf{j x}}$ & $\alpha-\mathbf{x}$ & A & $\mathbf{K}$ \\
\hline \multicolumn{8}{|c|}{ Positive impacts } \\
\hline & \multicolumn{7}{|l|}{ Socio-Economic Impact (SE): $\alpha=0.90$} \\
\hline SE1 & F1 brings economic benefits to the City of & 2.84 & 1.27 & 0.75 & 0.89 & 0.07 & -1.02 \\
\hline SE2 & Due to Formula 1, tourism has increased in __ throughout the year & 2.46 & 1.23 & 0.66 & 0.90 & 0.41 & -0.91 \\
\hline SE3 & F1 increases trade and local business & 2.90 & 1.26 & 0.77 & 0.88 & 0.03 & -1.04 \\
\hline SE4 & F1 increases private investment and business opportunities & 2.81 & 1.17 & 0.69 & 0.89 & 0.09 & -0.86 \\
\hline SE5 & Thanks to F1, employment in __ has improved & 2.18 & 1.14 & 0.69 & 0.89 & 0.61 & -0.61 \\
\hline SE6 & F1 increases consumption in the city. & 2.86 & 1.21 & 0.76 & 0.88 & -0.03 & -1.00 \\
\hline \multirow[t]{2}{*}{ SE7 } & F1 brings great benefits to the neighbourhood where it is held & 2.88 & 1.33 & 0.68 & 0.89 & 0.02 & -1.20 \\
\hline & \multicolumn{7}{|l|}{ Urban Development and Impact on Infrastructure (UD-I): $\alpha=0.91$} \\
\hline UD-I1 & F1 has improved the infrastructure in the city (accesses, streets, street furniture...) & 2.63 & 1.20 & 0.76 & 0.89 & 0.21 & -0.91 \\
\hline UD-I2 & F1 has improved the public transport system in & 2.42 & 1.19 & 0.76 & 0.89 & 0.40 & -0.78 \\
\hline UD-I3 & The infrastructures created by F1 are beneficial for the citizens & 2.28 & 1.20 & 0.76 & 0.89 & 0.57 & -0.71 \\
\hline UD-I4 & F1 has regenerated the infrastructure of the area (port, beaches, streets, street furniture...) & 2.94 & 1.21 & 0.74 & 0.89 & -0.07 & -0.94 \\
\hline UD-I5 & F1 has improved social services in the city & 2.16 & 1.14 & 0.74 & 0.89 & 0.64 & -0.52 \\
\hline \multirow[t]{2}{*}{ UD-I6 } & The infrastructures created by F1 are useful for other activities & 2.00 & 1.12 & 0.71 & 0.90 & 0.92 & -0.05 \\
\hline & \multicolumn{7}{|l|}{ Political and Administrative Impact (P-A): $\alpha=0.94$} \\
\hline P-A1 & F1 has improved __ image around the world & 3.13 & 1.27 & 0.86 & 0.92 & -0.14 & -1.04 \\
\hline P-A2 & The celebration of F1 has facilitated the opening of __ to the world & 3.06 & 1.25 & 0.87 & 0.92 & -0.11 & -1.02 \\
\hline P-A3 & _ F1 event increases international recognition of the country & 3.04 & 1.27 & 0.86 & 0.92 & -0.05 & -1.04 \\
\hline P-A4 & $\overline{\text { F1 }}$ shows the capacity of __ society to host and organize major sporting events & 2.86 & 1.30 & 0.81 & 0.93 & 0.05 & -1.08 \\
\hline \multirow[t]{2}{*}{ P-A5 } & F1 promotes the city as a tourist destination & 3.17 & 1.29 & 0.77 & 0.94 & -0.17 & -1.03 \\
\hline & \multicolumn{7}{|l|}{ Psychosocial Impact (PS): $\alpha=0.86$} \\
\hline PS1 & F1 makes me proud to live in & 2.05 & 1.26 & 0.79 & 0.73 & 0.91 & -0.37 \\
\hline PS2 & Celebrating F1 makes __ a safer city & 2.10 & 1.10 & 0.72 & 0.81 & 0.68 & -0.41 \\
\hline \multirow[t]{2}{*}{ PS3 } & Celebrating F1 makes__ a more attractive city to live in & 2.22 & 1.21 & 0.68 & 0.84 & 0.71 & -0.48 \\
\hline & \multicolumn{7}{|l|}{ Sports Impact (S): $\alpha=0.87$} \\
\hline S1 & I think that thanks to F1 there has been an increase in sports practice in the city of __ & 1.74 & 0.95 & 0.73 & 0.84 & 1.13 & 0.56 \\
\hline S2 & Thanks to F1 there has been an increase in sporting facilities & 1.82 & 0.95 & 0.77 & 0.83 & 0.97 & 0.25 \\
\hline S3 & F1 has increased subsidies and sporting support for the city's clubs & 1.80 & 0.94 & 0.72 & 0.84 & 0.93 & 0.10 \\
\hline S4 & F1 promotes motor sports in the country and gives new opportunities to young drivers & 2.49 & 1.14 & 0.66 & 0.86 & 0.27 & -0.74 \\
\hline S5 & F1 provides citizens with the opportunity to participate in the organization of major sporting events & 2.38 & 1.16 & 0.66 & 0.86 & 0.32 & -0.90 \\
\hline
\end{tabular}


Table 1. Cont

\begin{tabular}{|c|c|c|c|c|c|c|c|}
\hline & Items & $\mathbf{M}$ & SD & $\mathbf{r}_{\mathbf{j x}}$ & $\alpha-\mathbf{x}$ & A & $\mathbf{K}$ \\
\hline & \multicolumn{7}{|l|}{ Socio-Cultural Impact (SC): $\alpha=0.89$} \\
\hline SC1 & F1 is designed for the entertainment of citizens & 1.85 & 1.08 & 0.61 & 0.89 & 0.23 & -0.86 \\
\hline $\mathrm{SC} 2$ & $\mathrm{~F} 1$ provides citizens with an opportunity to meet new people & 2.52 & 1.14 & 0.75 & 0.86 & 0.46 & -0.68 \\
\hline SC3 & F1 improves the solidarity and hospitality of citizens with visitors & 2.33 & 1.15 & 0.79 & 0.85 & 0.38 & -0.80 \\
\hline SC4 & F1 encourages cultural exchange and understanding of other cultures & 2.48 & 1.21 & 0.78 & 0.85 & 0.96 & 0.23 \\
\hline SC5 & $\mathrm{F} 1$ promotes the preservation and conservation of the city culture & 1.90 & 1.04 & 0.74 & 0.87 & 0.24 & 0.96 \\
\hline \multicolumn{8}{|c|}{ Negative impacts } \\
\hline & \multicolumn{7}{|l|}{ Negative Socio-Economic Impact (SEN): $\alpha=0.86$} \\
\hline SEN1 & The celebration of the F1 raises the prices of goods and services in & 3.75 & 1.11 & 0.63 & 0.84 & -0.59 & -0.42 \\
\hline SEN2 & The F1 excessively alters the daily life of the residents & 3.31 & 1.31 & 0.64 & 0.83 & -0.21 & -1.08 \\
\hline SEN3 & I believe that $\mathrm{F} 1$ distorts and hinders the normal functioning of the city & 3.42 & 1.23 & 0.78 & 0.79 & -0.43 & -0.77 \\
\hline SEN4 & During the celebration of F1 many citizens avoid the area where the event was held & 3.85 & 1.15 & 0.63 & 0.83 & -0.77 & -0.18 \\
\hline \multirow[t]{2}{*}{ SEN5 } & F1 causes restrictions on access to public facilities and services & 3.62 & 1.19 & 0.67 & 0.82 & -0.30 & -0.90 \\
\hline & \multicolumn{7}{|l|}{ Negative Socio-Cultural Impact (SCN): $\alpha=0.81$} \\
\hline SCN1 & F1 encourages inappropriate behavior (consumption of drugs, alcohol, etc.) & 2.89 & 1.23 & 0.68 & 0.71 & 0.11 & -1.12 \\
\hline SCN2 & F1 encourages the development of dangerous driving behavior & 2.80 & 1.31 & 0.61 & 0.79 & 0.39 & -0.74 \\
\hline \multirow[t]{2}{*}{ SCN3 } & F1 increases levels of crime and vandalism in the city & 2.61 & 1.21 & 0.68 & 0.72 & 0.05 & -0.85 \\
\hline & \multicolumn{7}{|l|}{ Negative Environmental Impact (EN): $\alpha=0.87$} \\
\hline E1 & F1 causes damage to the environment and natural areas (beaches, port...) & 3.44 & 1.29 & 0.73 & 0.83 & -0.38 & -0.94 \\
\hline E2 & F1 increases the pollution of the city & 3.63 & 1.21 & 0.82 & 0.75 & -0.54 & -0.61 \\
\hline \multirow[t]{2}{*}{ E3 } & F1 increases the volume of waste in the area & 3.76 & 1.16 & 0.71 & 0.86 & -0.67 & -0.38 \\
\hline & \multicolumn{7}{|l|}{ Fair social distribution (FSD) $\alpha=0.85$} \\
\hline FSD1 & In general, I think that investing in F1 is beneficial for the citizens & 2.12 & 1.24 & 0.75 & 0.57 & 0.81 & -0.45 \\
\hline \multirow[t]{2}{*}{ FSD2 } & In general, I believe that the costs and benefits of $\mathrm{F} 1$ are distributed equitably in the city society & 1.82 & 1.06 & 0.75 & 0.57 & 1.12 & 0.41 \\
\hline & \multicolumn{7}{|l|}{ Future intentions (FI) $\alpha=0.91$} \\
\hline FI1 & I would like to attend as a spectator at the F1 & 2.84 & 1.58 & 0.75 & 0.91 & 0.11 & -1.54 \\
\hline FI2 & I'd like to see F1 continue to be held in __ & 2.42 & 1.43 & 0.79 & 0.90 & 0.56 & -1.02 \\
\hline FI3 & In the conversations I have I speak in favour of F1 & 2.42 & 1.35 & 0.85 & 0.88 & 0.50 & -0.91 \\
\hline FI4 & If someone asks me for my opinion, I will recommend him to attend F1 as a spectator & 2.52 & 1.34 & 0.86 & 0.87 & 0.43 & -0.98 \\
\hline
\end{tabular}


Table 2 shows the goodness-of-fit indices of the first- and second-order models of the two scales of perceived impacts. It can be seen that both the scale of perceived positive impacts and the scale of perceived negative impacts show a good fit, both in the first-order factorial solution with the correlated factors (model 3) and in the second-order one (model 4), with slight differences between the two. The second-order factor model was chosen because it had acceptable adjustment rates compared to the correlated first-order factor solution, which could present problems of discriminant validity [58].

Table 2. Model fit comparison.

\begin{tabular}{|c|c|c|c|c|c|c|}
\hline Model & $\begin{array}{c}\text { S-B } \chi^{2} \\
\text { (df) }\end{array}$ & $\begin{array}{c}\chi^{2} \\
\text { (df) }\end{array}$ & RMSEA & CFI & NNFI & IFI \\
\hline \multicolumn{7}{|l|}{ Positive Impacts } \\
\hline 1. First order factor & $2010.92(434)$ & $2610.10(434)$ & 0.099 & 0.83 & 0.81 & 0.83 \\
\hline 2. Six first-order factors (uncorrelated) & $2522.62(434)$ & $2933.60(434)$ & 0.114 & 0.77 & 0.75 & 0.77 \\
\hline 3. Six first-order factors (correlated) & $957.57(419)$ & $1210.84(419)$ & 0.059 & 0.94 & 0.93 & 0.94 \\
\hline 4. Second order factor & $1009.35(425)$ & $1285.05(425)$ & 0.061 & 0.94 & 0.93 & 0.94 \\
\hline \multicolumn{7}{|l|}{ Negative Impacts } \\
\hline 1. First order factor & $395.73(44)$ & $544.53(44)$ & 0.147 & 0.82 & 0.77 & 0.82 \\
\hline 2. Three first-order factors (uncorrelated) & $463.01(44)$ & $555.23(44)$ & 0.160 & 0.78 & 0.72 & 0.78 \\
\hline 3. Three first-order factors (correlated) & $144.32(41)$ & $196.75(41)$ & 0.082 & 0.95 & 0.93 & 0.95 \\
\hline 4. Second order factor & $139.19(41)$ & $187.10(41)$ & 0.080 & 0.95 & 0.93 & 0.95 \\
\hline
\end{tabular}

To analyze reliability, Cronbach's alpha, Composite Reliability (CR), and Average Variance Extracted (AVE) measurements were observed (see Tables 1 and 3). Cronbach's alpha values were higher than 0.70 , for all factors and scales, as recommended by the literature [54]. This criterion was also met for the CR values [56], with values ranging from 0.81 to 0.94. Finally, for AVE values, all factors were found to have values greater than the 0.50 , as recommended by the literature [59].

Table 3. Factor loadings, composite reliability and average variance extracted of the scale dimensions.

\begin{tabular}{|c|c|c|c|}
\hline Dimensions & Std. Factor Loading & $\mathrm{CR}^{1}$ & $\mathrm{AVE}^{2}$ \\
\hline \multicolumn{4}{|l|}{ Positive impacts } \\
\hline Socio-Economic Impact (SE) & & 0.90 & 0.58 \\
\hline SE1 & 0.78 & & \\
\hline SE2 & 0.69 & & \\
\hline SE3 & 0.80 & & \\
\hline SE4 & 0.74 & & \\
\hline SE5 & 0.73 & & \\
\hline SE6 & 0.81 & & \\
\hline SE7 & 0.76 & & \\
\hline Urban Development and Impact on Infrastructure (UD-I) & & 0.91 & 0.62 \\
\hline UD-I1 & 0.79 & & \\
\hline UD-I2 & 0.81 & & \\
\hline UD-I3 & 0.79 & & \\
\hline UD-I4 & 0.77 & & \\
\hline UD-I5 & 0.81 & & \\
\hline UD-I6 & 0.75 & & \\
\hline Political and Administrative Impact (P-A) & & 0.94 & 0.76 \\
\hline P-A1 & 0.90 & & \\
\hline P-A2 & 0.90 & & \\
\hline P-A3 & 0.90 & & \\
\hline P-A4 & 0.85 & & \\
\hline P-A5 & 0.80 & & \\
\hline
\end{tabular}


Table 3. Cont.

\begin{tabular}{|c|c|c|c|}
\hline Dimensions & Std. Factor Loading & $\mathrm{CR}^{1}$ & $\mathrm{AVE}^{2}$ \\
\hline Psychosocial Impact (PS) & & 0.86 & 0.67 \\
\hline PS1 & 0.87 & & \\
\hline PS2 & 0.79 & & \\
\hline PS3 & 0.80 & & \\
\hline Sports Impact (S) & & 0.88 & 0.60 \\
\hline S1 & 0.82 & & \\
\hline $\mathrm{S} 2$ & 0.85 & & \\
\hline S3 & 0.80 & & \\
\hline S4 & 0.68 & & \\
\hline S5 & 0.71 & & \\
\hline Socio-Cultural Impact (SC) & & 0.89 & 0.63 \\
\hline SC1 & 0.68 & & \\
\hline SC2 & 0.80 & & \\
\hline SC3 & 0.86 & & \\
\hline SC4 & 0.82 & & \\
\hline SC5 & 0.79 & & \\
\hline \multicolumn{4}{|l|}{ Negative impact } \\
\hline Negative Socio-Economic Impact (SEN) & & 0.86 & 0.59 \\
\hline SEN1 & 0.71 & & \\
\hline SEN2 & 0.75 & & \\
\hline SEN3 & 0.85 & & \\
\hline SEN4 & 0.67 & & \\
\hline SEN5 & 0.72 & & \\
\hline Negative Socio-Cultural Impact (SCN) & & 0.81 & 0.59 \\
\hline SCN1 & 0.79 & & \\
\hline SCN2 & 0.69 & & \\
\hline SCN3 & 0.82 & & \\
\hline Negative Environmental Impact (EN) & & 0.87 & 0.70 \\
\hline EN1 & 0.82 & & \\
\hline EN2 & 0.89 & & \\
\hline EN3 & 0.79 & & \\
\hline Fair social distribution (FSD) & & 0.86 & 0.76 \\
\hline FSD1 & 0.93 & & \\
\hline FSD2 & 0.81 & & \\
\hline Future intentions (FI) & & 0.92 & 0.74 \\
\hline FI1 & 0.77 & & \\
\hline FI2 & 0.82 & & \\
\hline FI3 & 0.91 & & \\
\hline FI4 & 0.92 & & \\
\hline
\end{tabular}

${ }^{1} \mathrm{CR}=$ Composite Reliability ${ }^{2}$ AVE $=$ Average Variance Extracted.

To analyze the convergent validity, the values of the $t$-tests associated with the factorial loads of the items were found to be greater than $1.96(p<0.05)$, ranging from 10.81 to 34.80 for the indicators of the scale of perceived positive impacts, and between 13.69 and 24.26 for the items of the scale of negative impacts. The factor loadings of all items were also found to be greater than 0.50 . As regards the discriminant validity, on the one hand, we found that the correlation between the two factors was less than 0.85 (see Table 4). On the other hand, we found that the square root of the AVE was higher than the correlation between pairs of factors, and this criterion was also fulfilled, although the square root of the AVE and the correlation between the sociocultural and psychosocial impact factors had the same value (0.79). Therefore, we decided to test the adjustment of the model by creating a dimension that included the items of these two dimensions. However, the results showed that the overall adjustment of the scale was worsening and reflected established correlations between this new 
dimension and the sports impact factor, so we decided to maintain the first-order factor structure composed of the six factors indicated.

Table 4. Discriminant validity and correlations among variables.

\begin{tabular}{|c|c|c|c|c|c|c|}
\hline & F1-SE & F2-UD-I & F3-P-A & F4-PS & F5-S & F6-SC \\
\hline \multicolumn{7}{|l|}{ Positive impacts } \\
\hline F1-Socio-Economic Impact (SE) & 0.76 & & & & & \\
\hline F2-Urban Development and Impact on Infrastructure (UD-I) & $0.74 * *$ & 0.79 & & & & \\
\hline F3-Political and Administrative Impact (P-A) & $0.75 * *$ & $0.67^{* *}$ & 0.87 & & & \\
\hline F4-Psychosocial Impact (PS) & $0.70 * *$ & $0.70^{* *}$ & $0.75^{* *}$ & 0.82 & & \\
\hline F5-Sports Impact (S) & $0.63 * *$ & $0.66^{* *}$ & $0.63 * *$ & $0.72 * *$ & 0.77 & \\
\hline F6-Socio-Cultural Impact (SC) & $0.68^{* *}$ & $0.69^{* *}$ & $0.70^{* *}$ & $0.79 * *$ & $0.73^{* *}$ & 0.79 \\
\hline Negative impacts & F1-SEN & F2-SCN & F3-EN & & & \\
\hline F1-Negative Socio-Economic Impact (SEN) & 0.74 & & & & & \\
\hline F2-Negative Socio-Cultural Impact (SCN) & $0.45^{* *}$ & 0.77 & & & & \\
\hline F3-Negative Environmental Impact (EN) & $0.69 * *$ & $0.57 * *$ & 0.84 & & & \\
\hline
\end{tabular}

Note: ${ }^{* *} p<0.01$. The diagonal scores indicate the square root of the average variance extracted (AVE).

\subsection{Relationship between Constructs and the Mediating Effect}

The four steps outlined by Baron and Kenny [60] and the application of the Sobel test were followed to verify the mediating effect of FSD. Table 5 shows the standardized coefficients and the value of the $t$-test for each of the three models produced, in order to check the mediating effect. These models show the results of the relationships between the constructs under study: positive impacts, negative impacts, FSD, and future intentions with respect to the European Formula 1 Grand Prix.

Table 5. Findings of the proposed model and the mediation tests.

\begin{tabular}{|c|c|c|c|c|}
\hline \multirow[b]{2}{*}{ Hypothesized Paths } & \multicolumn{2}{|c|}{ Direct Effects } & \multicolumn{2}{|c|}{ Mediation Test } \\
\hline & $\begin{array}{l}\text { Standardized } \\
\text { Coefficient }\end{array}$ & $t$-Value & $\begin{array}{l}\text { Standardized } \\
\text { Coefficient }\end{array}$ & $t$-Value \\
\hline H1: Positive impacts-FSD & $0.84 * *$ & 15.42 & & \\
\hline H2: Negative impacts-FSD & $-0.31^{* *}$ & -7.16 & & \\
\hline H3: FSD—Future intentions & $0.85^{* *}$ & 15.87 & & \\
\hline \multicolumn{5}{|c|}{ H4: Step 1. Independent variables-Dependent variable } \\
\hline Positive impacts-IF & & & $0.76^{* *}$ & 13.50 \\
\hline Negative impacts-IF & & & $-0.25 * *$ & -6.12 \\
\hline \multicolumn{5}{|c|}{ H4: Step 2. Independent variables-Mediating variable } \\
\hline Positive impacts—FSD & & & $0.79^{* *}$ & 15.09 \\
\hline Negative impacts_FSD & & & $-0.31 * *$ & -6.78 \\
\hline \multicolumn{5}{|c|}{$\begin{array}{c}\text { H4: Steps } 3 \text { and } 4 \text {. Independent variables and mediating } \\
\text { variable-Dependent variable }\end{array}$} \\
\hline Positive impacts-IF & & & $0.58^{* *}$ & 10.59 \\
\hline Negative impacts-IF & & & $-0.18^{* *}$ & -4.40 \\
\hline FSD-Future intentions & & & $0.46^{* *}$ & 8.53 \\
\hline
\end{tabular}

Note: ${ }^{* *} p<0.01$.

The proposed model (previously shown in Figure 1) presents a good fit of the main reference indicators: $\chi^{2} / \mathrm{df}=2.46$; RMSEA $=0.053 ; \mathrm{NNFI}=0.91 ; \mathrm{CFI}=0.92 ;$ and IFI $=0.92$. The results allow H1 and $\mathrm{H} 2$ to be confirmed, since a significant positive relationship was observed between the perception on positive impacts and the perception on $\operatorname{FSD}(\beta=0.84, t=15.42, p<0.01)$ and a negative relationship was observed between the perceived negative impacts and FSD $(\beta=-0.31, t=-7.16, p<0.01)$. Moreover, $\mathrm{H} 3$ was confirmed, as the results show a significant and positive relationship between the perception on FSD and future intentions $(\beta=0.85, t=15.878, p<0.01$ ).

For there to be mediation between the independent variables (perceived positive and negative impacts) and the mediating variable (perception of a fair social distribution) and the dependent variable (future intentions), they must be significantly related (steps 1 and 2). When the mediating variable is 
introduced, the relationship between the independent and dependent variables must be significantly reduced (steps 3 and 4). Full mediation is established when the standardized coefficients of the independent variables in step 1 are significant and the same coefficients are not significant in step 4 [2]. Otherwise, assuming that the four conditions are maintained, partial mediation is supported $[2,60]$.

The Step 1 and Step 2 models explained $64 \%\left(R^{2}=0.64\right)$ and $72 \%\left(R^{2}=0.72\right)$, respectively. In Step 3 and Step 4 , the results confirm the significant relationship between the FSD (mediator) and future intentions ( $\beta=0.46, t=8.53, p<0.01$ ), proving that the other two independent variables in this model are significantly related, but reduce their coefficient by introducing the mediating variable as one more independent variable.

Finally, the Sobel test was applied to check the existence of mediation effects. This test allowed us to verify the existence of a mediating effect of the perception on FSD between the positive impacts and the future intentions $(z=7.47, p<0.01)$ and between the negative impacts and future intentions $(z=5.34$, $p<0.01$ ). This effect was partially mediated because the coefficients of the perceived impacts in step 4 were significantly related to future intentions, so a complete mediation could not be established $[2,60]$. In conclusion, the results confirm $\mathrm{H} 4$ and $\mathrm{H} 5$ since the mediating effect of the perception on FSD on the relationship between positive and negative perceived impacts and future intentions was verified.

\section{Discussion and Conclusions}

This study analyzes the influence of perception on the fair social distribution of benefits and costs associated with holding a major sports event on future intentions or behavior regarding the event. Specifically, we tested the mediating effect of FSD between perceived positive and negative impacts and future intentions.

Firstly, we checked the adjustment of the scale of perceived positive and negative impacts, observing a good adjustment in both the first- and second-order factor structure in the two scales. In this sense, we decided to use the second-order model to check the mediating effect of FSD between perceived impacts and future intentions. According to Ma and Kaplanidou [22], the higher-order model allows for the distinction of first-order factors, identifying the effect of the most important impacts on the mediating and outcome variables.

On the other hand, the structural model allowed the relationship between the different constructs under study to be tested. First, it was found that as the favorable perception of the positive impacts increases, the event is perceived to be more equitable at the social level. Conversely, if the perception of negative impacts increases, the assessment of the possibility of the event being perceived as more equitable at the social level decreases. In this sense, special attention should be paid to the perceived negative impacts, because they are the ones that can determine a negative perception of FSD, and it is necessary to minimize this type of impact on the host community in order to achieve a greater social balance. Ideally, the hosting of a sporting event should not result in social imbalance that harms some groups and benefits others. Therefore, in some cases, some form of compensation is needed for those who suffer from the effects of negative impacts without compensation in benefits.

It was also found that a higher positive assessment of the event in terms of FSD increased the probability of showing favorable intentions or behaviors. This result is consistent with other work that has analyzed the antecedents of future intentions and support for sports events [38]. In accordance with the SET, the theoretical framework has mentioned the need for perceived benefits or positive impacts to exceed perceived costs or negative impacts, in order to positively assess the social exchange derived from hosting a major sporting event. Therefore, if there is a positive perception on the balanced distribution of benefits and costs in the host community, there may be a greater degree of support for the holding of the event [38].

Finally, the partial mediating effect of FSD between perceived positive and negative impacts and future intentions was tested, confirming the importance of this variable in influencing the relationship between perceived impacts and future intentions. The SET allows for the understanding that a positive FSD assessment of the benefits and costs associated with a sports event will increase the probability of 
supporting the holding of a sports event and, therefore, of showing positive future intentions with respect to it. However, it could not be confirmed that this effect was fully mediated because the perceived impacts were also significantly related to the future intentions of the residents, although the predictive strength decreased significantly when the FSD variable was introduced into the model. The relationship between perceived impacts and future intentions has been contrasted in other work on sporting events with different characteristics $[40,41]$.

Therefore, special attention should be paid to the formation of the perceptions of residents of the host community of a sports event. The study suggests that it is important for organizers to pay attention to the social imbalances and injustices that may be associated with the hosting of major sporting events, in order to improve the assessment of perceived impacts and future intentions.

\subsection{Theoretical Implications}

The model allowed the influence of the FSD variable between the perception of positive and negative impacts and future intentions to be verified. Therefore, a favorable perception of positive impacts increases the positive assessment of FSD, while a high perception of negative impacts decreases the positive assessment of FSD, which, in turn, is positively related to future intentions. This means that a favorable perception of positive impacts and FSD contributes to developing positive future behaviors or intentions with regard to hosting future sports events, while a high perception of negative impacts contributes to decreasing the likelihood of favorable future intentions towards hosting future sports events. The FSD variable plays a relevant role in the relationships established between the perceived impacts and the future intentions of residents with respect to the holding of sporting events.

\subsection{Managerial Implications}

This work highlights the need for sports administrations and event organizers to take into account, in addition to perceived impacts, other variables that can influence the relationships between perceived impacts and future intentions, as is the case with the FSD. Considering only the perceived impacts and their relationship with future intentions and other outcome variables, such as support for the holding of the events, which is widely contrasted, can provide incomplete information for decision-making in planning future sporting events. Therefore, it is essential to plan sporting events by taking into account their long-term social sustainability, in order to contribute to a better assessment of the FSD associated with the benefits and costs related to the holding of these events. This implies planning, in advance, a fair social distribution of the benefits and costs of hosting the event among the different stakeholders in the host community. Finally, it would be advisable to incorporate different representatives of groups affected by the event into the organizing committee. In this way, it is possible to know, share and solve their possible concerns and needs about the impact that the event may have on their environment. This would make it easier for the stakeholders to perceive that the impact of the event on the community is fairer in both the negative and positive impacts.

\subsection{Limitations and Future Lines of Research}

This work has some limitations. Firstly, convenience sampling was used, so caution should be exercised when generalizing the results for the whole population. Nevertheless, an attempt has been made to balance the representation of the groups of residents based on the main socio-demographic variables.

Second, the sample was collected a few months after the event. Although this could be a limitation, we think this allowed residents to have more information about the impacts the event had, permitting them to make a more realistic assessment. In any case, future work should include various consultations, before, during, and after the event, as it has been shown that perceptions of the impacts of sporting events change over time.

Third, this study has worked with second-order factor models to group the categories of perceived impacts at the positive and negative level, in order to operate with two generic constructs of perceived impacts. Although this model proved to be effective in measuring the relationships between the 
constructs in this study, it did not prove the degree of influence that each impact category could independently have on the FSD and future intentions. Due to the fact that the mediating role of the FSD variable between each category of perceived positive and negative impacts and future intentions may vary, it would be advisable to check this degree of association per impact category in future research. Likewise, the moderating effect of this variable and others on the relations between perceived impacts and future intentions and support for the holding of events should be checked.

Author Contributions: Conceptualization, D.P.-C. and F.C.-M.; methodology, D.P.-C.; software, D.P.-C.; validation, D.P.-C., and M.A.; formal analysis, D.P.-C. and M.A.; investigation, D.P.-C. and M.A.; resources, M.A.; data curation, D.P.-C. and M.A.; writing-original draft preparation, D.P.-C.; writing-review and editing, D.P.-C., M.A. and F.C.-M.; visualization, M.A.; supervision, F.C.-M.; project administration, F.C.-M. All authors have read and agreed to the published version of the manuscript.

Funding: This research received no external funding.

Conflicts of Interest: The authors declare no conflict of interest.

\section{References}

1. Mao, L.L.; Huang, H. Social impact of Formula One Chinese Grand Prix: A comparison of local residents' perceptions based on the intrinsic dimension. Sport Manag. Rev. 2016, 19, 306-318. [CrossRef]

2. Prayag, G.; Hosany, S.; Nunkoo, R.; Alders, T. London residents' support for the 2012 Olympic Games: The mediating effect of overall attitude. Tour. Manag. 2013, 36, 629-640. [CrossRef]

3. Parra, D.; Calabuig, F.; Núñez, J.M.; Crespo, J. The Relevance of the Social Impact of Sports Events in the Context of Public Financing of Sport. In Sport Entrepreneurship and Innovation; Alonso Dos Santos, M., Ed.; Routledge: New York, NY, USA, 2017; pp. 117-140.

4. Balduck, A.L.; Maes, M.; Buelens, M. The Social Impact of the Tour de France: Comparisons of Residents' Pre- and Post-event Perceptions. Eur. Sport Manag. Q. 2011, 11, 91-113. [CrossRef]

5. Parra-Camacho, D.; Aguado-Berenguer, S.; Núñez-Pomar, J.M. Costs of holding a sporting event: The host community perception. J. Sports Econ. Manag. 2015, 5, 17-36.

6. Gursoy, D.; Milito, M.C.; Nunkoo, R. Residents' support for a mega-event: The case of the 2014 FIFA World Cup, Natal, Brazil. J. Destin. Mark. Manag. 2017, 6, 344-352. [CrossRef]

7. Gursoy, D.; Kendall, K. Hosting mega events. Ann. Tour. Res. 2006, 33, 603-623. [CrossRef]

8. Kim, C.; Kaplanidou, K. The Effect of Sport Involvement on Support for Mega Sport Events: Why Does It Matter. Sustainability 2019, 11, 5687. [CrossRef]

9. Zhou, Y.; Ap, J. Residents' Perceptions towards the Impacts of the Beijing 2008 Olympic Games. J. Travel Res. 2008, 48, 78-91. [CrossRef]

10. Gursoy, D.; Chi, C.G.; Ai, J.; Chen, B.T. Temporal Change in Resident Perceptions of a Mega-event: The Beijing 2008 Olympic Games. Tour. Geogr. 2011, 13, 299-324. [CrossRef]

11. Sánchez-Sáez, J.A.; Segado-Segado, F.; Vidal, A. Sports events socially responsible as the engine for local development. J. Sports Econ. Manag. 2018, 8, 172-186.

12. Getz, D.; Page, S.J. Progress and prospects for event tourism research. Tour. Manag. 2016, 52, $593-631$. [CrossRef]

13. Kaplanidou, K.; Karadakis, K.; Gibson, H.; Thapa, B.; Walker, M.; Geldenhuys, S.; Coetzee, W.J. Quality of Life, Event Impacts, and Mega-Event Support among South African Residents before and after the 2010 FIFA World Cup. J. Travel Res. 2013, 52, 631-645. [CrossRef]

14. Pappas, N. Hosting mega events: Londoners' support of the 2012 Olympics. J. Hosp. Tour. Manag. 2014, 21, 10-17. [CrossRef]

15. Ouyang, Z.; Gursoy, D.; Sharma, B. Role of trust, emotions and event attachment on residents' attitudes toward tourism. Tour. Manag. 2017, 63, 426-438. [CrossRef]

16. Waitt, G. Social impacts of the Sydney Olympics. Ann. Tour. Res. 2003, 30, 194-215. [CrossRef]

17. Ap, J. Residents' perceptions on tourism impacts. Ann. Tour. Res. 1992, 19, 665-690. [CrossRef]

18. Andriotis, K.; Vaughan, R.D. Urban Residents' Attitudes toward Tourism Development: The Case of Crete. J. Travel Res. 2003, 42, 172-185. [CrossRef] 
19. Kim, W.; Jun, H.M.; Walker, M.; Drane, D. Evaluating the perceived social impacts of hosting large-scale sport tourism events: Scale development and validation. Tour. Manag. 2015, 48, 21-32. [CrossRef]

20. Preuss, H.; Solberg, H.A. Attracting Major Sporting Events: The Role of Local Residents. Eur. Sport Manag. Q. 2006, 6, 391-411. [CrossRef]

21. Fredline, L. Host community reactions to motorsport events: The perception of impact on quality of life. In Sport Tourism: Interrelationships, Impacts and Issues; Ritchie, B.W., Adair, A., Eds.; Channel View Publications: Clevedon, UK, 2004; pp. 155-173.

22. Ma, S.C.; Kaplanidou, K. Examining the Importance of Legacy Outcomes of Major Sport Events for Host City Residents' Quality of Life. Appl. Res. Qual. Life 2016, 12, 903-923. [CrossRef]

23. Parra-Camacho, D.; Calabuig, F.; Añó, V.; Ayora, D.; Núñez-Pomar, J.M. The impact of a medium-size sporting event: The host community perceptions. Retos 2014, 26, 88-93.

24. González-García, R.J.; Parra, D.; Calabuig, F.; Añó, V. Residents' perception regarding Mundobasket 2014 in Gran Canaria (Spain) and support to sport events celebration. Rev. Iberoam. Psicol. Ejerc. Deporte 2016, 11, 279-288.

25. Kim, H.J.; Gursoy, D.; Lee, S.-B. The impact of the 2002 World Cup on South Korea: Comparisons of pre- and post-games. Tour. Manag. 2006, 27, 86-96. [CrossRef]

26. Ritchie, B.W.; Shipway, R.; Cleeve, B. Resident Perceptions of Mega-Sporting Events: A Non-Host City Perspective of the 2012 London Olympic Games. J. Sport Tour. 2009, 14, 143-167. [CrossRef]

27. Triantafyllidis, S.; Ries, R.; Kaplanidou, K. Carbon Dioxide Emissions of Spectators' Transportation in Collegiate Sporting Events: Comparing On-Campus and Off-Campus Stadium Locations. Sustainability 2018, 10, 241. [CrossRef]

28. Karadakis, K.; Kaplanidou, K. Legacy perceptions among host and non-host Olympic Games residents: A longitudinal study of the 2010 Vancouver Olympic Games. Eur. Sport Manag. Q. 2012, 12, $243-264$. [CrossRef]

29. Collins, A.; Flynn, A.; Munday, M.; Roberts, A. Assessing the Environmental Consequences of Major Sporting Events: The 2003/04 FA Cup Final. Urban Stud. 2007, 44, 457-476. [CrossRef]

30. Chalip, L. Towards Social Leverage of Sport Events. J. Sport Tour. 2006, 11, 109-127. [CrossRef]

31. Taks, M.; Kesenne, S.; Chalip, L.; Green, C.; Martyn, S. Economic Impact Analysis versus Cost Benefit Analysis: The Case of a Medium-Sized Sport Event. Int. J. Sport Financ. 2011, 6, 187-203.

32. Taks, M. Social sustainability of non-mega sport events in a global world1. Eur. J. Sport Soc. 2013, 10, 121-141. [CrossRef]

33. Kaplanidou, K. The importance of legacy outcomes for Olympic Games four summer host cities residents' quality of life: 1996-2008. Eur. Sport Manag. Q. 2012, 12, 397-433. [CrossRef]

34. Fredline, E. Host Community Reactions Major Sporting Events: The Gold Coast Indy and the Australian Formula One Grand Prix in Melbourne; Griffith University: Brisbane, Australia, 2000.

35. Misener, L.; McGillivray, D.; McPherson, G.; Legg, D. Leveraging parasport events for sustainable community participation: The Glasgow 2014 Commonwealth Games. Ann. Leis. Res. 2015, 18, 450-469. [CrossRef]

36. Smith, A. Leveraging sport mega-events: New model or convenient justification? J. Policy Res. Tour. Leis. Events 2013, 6, 15-30. [CrossRef]

37. Fredline, E.; Faulkner, B. Variations in Residents' Reactions to Major Motorsport Events: Why Residents Perceive the Impacts of Events Differently. Event Manag. 2001, 7, 115-125. [CrossRef]

38. Parra-Camacho, D.; Alonso Dos Santos, M.; Duclos Bastias, D. The relationship between factors that contribute to support and future intentions in relation to a major sporting event. Acad. Rev. Latinoam. Adm. 2019, 32, 442-454. [CrossRef]

39. Chien, P.M.; Ritchie, B.W.; Shipway, R.; Henderson, H. I Am Having a Dilemma Factors Affecting Resident Support of Event Development in the Community. J. Travel Res. 2012, 51, 451-463. [CrossRef]

40. Parra-Camacho, D.; González-García, R.J.; Añó, V.; Ayora, D. Visitors' perception on the social impact and intentions regarding holding a small-scale sporting event. Rev. Psicol. Deporte 2016, 25, 93-96.

41. Inoue, Y.; Havard, C.T. Determinants and Consequences of the Perceived Social Impact of a Sport Event. J. Sport Manag. 2014, 28, 295-310. [CrossRef]

42. Oshimi, D.; Harada, M. Host residents' role in sporting events: The city image perspective. Sport Manag. Rev. 2019, 22, 263-275. [CrossRef] 
43. Zhou, Y. Resident Perceptions Toward the Impacts of the Macao Grand Prix. J. Conv. Event Tour. 2010, 11, 138-153. [CrossRef]

44. Fredline, L.; Jago, L.; Deery, M. The Development of a Generic Scale to Measure the Social Impacts of Events. Event Manag. 2003, 8, 23-37. [CrossRef]

45. Añó, V.; Calabuig, F.; Parra, D. Social impact of a major sport event: The Formula 1 Grand Prix of Europe. Cult. Cienc. Deporte 2012, 7, 53-65. [CrossRef]

46. Brady, M.; A Knight, G.; Croninjr, J.; Tomás, G.; Hult, G.T.M.; Keillor, B. Removing the contextual lens: A multinational, multi-setting comparison of service evaluation models. J. Retail. 2005, 81, 215-230. [CrossRef]

47. Chou, C.-P.; Bentler, P.M.; Satorra, A. Scaled test statistics and robust standard errors for non-normal data in covariance structure analysis: A Monte Carlo study. Br. J. Math. Stat. Psychol. 1991, 44, 347-357. [CrossRef] [PubMed]

48. Kline, R.B. Principles and Practice of Structural Equation Modeling, 4th ed.; Guilford Publications: New York, NY, USA, 2015.

49. Satorra, A.; Bentler, P.M. Corrections to Test Statistics and Standard Errors in Covariance Structure Analysis. In Latent Variables Analysis: Applications for Developmental Research; von Eye, A., Clogg, C.C., Eds.; Sage: Thousand Oaks, CA, USA, 1994.

50. Wheaton, B.; Muthén, B.; Alwin, D.F.; Summers, G.F. Assessing Reliability and Stability in Panel Models. Sociol. Methodol. 1977, 8, 84. [CrossRef]

51. Byrne, B.M. Structural Equation Modeling with Mplus: Basic Concepts, Applications, and Programming; Routledge: Abingdon, UK, 2013; ISBN 978-1-136-66346-8.

52. Maccallum, R.C.; Austin, J.T. Applications of Structural Equation Modeling in Psychological Research. Annu. Rev. Psychol. 2000, 51, 201-226. [CrossRef]

53. Browne, M.W.; Cudeck, R. Alternative Ways of Assessing Model Fit. Sociol. Methods Res. 1992, 21, $230-258$. [CrossRef]

54. Hair, J.F.; Black, W.C.; Babin, B.J.; Anderson, R.E. Multivariate Data Analysis, 7th ed.; Pearson: London, UK, 2014.

55. Anderson, J.; Gerbing, D. Structural Equation Modeling in Practice: A Review and Recommended Two-Step Approach. Psychol. Bull. 1988, 103, 411-423. [CrossRef]

56. Fornell, C.; Larcker, D.F. Evaluating Structural Equation Models with Unobservable Variables and Measurement Error. J. Mark. Res. 1981, 18, 39-50. [CrossRef]

57. Chou, C.-P.; Bentler, P.M. Estimates and Tests in Structural Equation Modeling. In Structural Equation Modeling: Concepts, Issues, and Applications; Sage Publications, Inc.: Thousand Oaks, CA, USA, 1995; pp. 37-55.

58. Marsh, H.W.; Hocevar, D. Application of confirmatory factor analysis to the study of self-concept: First- and higher order factor models and their invariance across groups. Psychol. Bull. 1985, 97, 562-582. [CrossRef]

59. Bagozzi, R.P.; Yi, Y. On the evaluation of structural equation models. JAMS 1988, 16, 74-94. [CrossRef]

60. Baron, R.M.; Kenny, D.A. The moderator-mediator variable distinction in social psychological research: Conceptual, strategic, and statistical considerations. J. Personal. Soc. Psychol. 1986, 51, 1173-1182. [CrossRef] 